Ann. Geophysicae 16, 764-774 (1998) @ EGS - Springer-Verlag 1998

\title{
Interhemispheric contrasts in the ionospheric convection response to changes in the interplanetary magnetic field and substorm activity: a case-study
}

\author{
B. A. Shand ${ }^{1}$, T. K. Yeoman ${ }^{1}$, R. V. Lewis ${ }^{2}$, R. A. Greenwald ${ }^{3}$, M. R. Hairston ${ }^{4}$ \\ ${ }^{1}$ Department of Physics and Astronomy, University of Leicester, University Road, Leicester, LE1 7RH, UK \\ e-mail: yxo@ion.le.ac.uk \\ ${ }^{2}$ NERC, British Antarctic Survey, Madingley Road, Cambridge, CB3 OET, UK \\ ${ }^{3}$ Johns Hopkins University, Applied Physics Laboratory, Laurel, MD 20707, USA \\ ${ }^{4}$ Center for Space Sciences, The University of Texas at Dallas, Richardson, Texas, USA
}

Received: 24 October 1997 / Revised: 16 February 1998 / Accepted: 18 February 1998

\begin{abstract}
Interhemispheric contrasts in the ionospheric convection response to variations of the interplanetary magnetic field (IMF) and substorm activity are examined, for an interval observed by the Polar AngloAmerican Conjugate Experiment (PACE) radar system between $\sim 1600$ and $\sim 2100$ MLT on 4 March 1992. Representations of the ionospheric convection pattern associated with different orientations and magnitudes of the IMF and nightside driven enhancements of the auroral electrojet are employed to illustrate a possible explanation for the contrast in convection flow response observed in radar data at nominally conjugate points. Ion drift measurements from the Defence Meteorological Satellite Program (DMSP) confirm these ionospheric convection flows to be representative for the prevailing IMF orientation and magnitude. The location of the fields of view of the PACE radars with respect to these patterns suggest that the radar backscatter observed in each hemisphere is critically influenced by the position of the ionospheric convection reversal boundary (CRB) within the radar field of view and the influence it has on the generation of the irregularities required as scattering targets by high-frequency coherent radar systems. The position of the CRB in each hemisphere is strongly controlled by the relative magnitudes of the IMF $B_{z}$ and $B_{y}$ components, and hence so is the interhemispheric contrast in the radar observations.
\end{abstract}

Key words. Magnetospheric physics - Auroral phenomena - Magnetosphere-ionosphere interactions · Storms and substorms

\section{Introduction}

A number of so-called conjugate studies were carried out during the 1950s and 1960s (see reviews by Wescott, 1966; Oguti, 1969; Nagata, 1987). Any such review is complicated by the lack of a comprehensive definition of the terminology which may be employed to describe interhemispheric phenomena. The term "conjugate" can be defined as "to undergo inflection according to a specific set of rules". It is these specific rules which should be outlined prior to continuing with any discussion of conjugate or, possibly more appropriately, interhemispheric phenomena. Geomagnetic conjugate points are usually derived from empirical models of the Earth's internal magnetic field and do not fully represent the linkage of field lines in the northern and southern auroral zone, resulting in the displacement of observed interhemispheric phenomena from their "internal-field conjugate" points. In this paper we will define three levels of conjugacy; firstly phenomena which map between hemispheres according to the geomagnetic field model employed, referred to as conjugate. Secondly, displaced conjugacy, is defined as occurring when a conjugate feature is displaced some distance from its nominal conjugate point, although it is still observed within the field of view of the observing instrumentation. Finally, non-conjugacy is defined as the situation in which the auroral phenomenon is observed within the field of view of the observing instrumentation in only one hemisphere. In each of these cases it is important to define the field model in determining a nominal conjugate point and in this investigation we employ the Altitude Adjusted Corrected GeoMagnetic system (AACGM, based on Baker and Wing, 1989) in discussing the inter-hemispheric observation of auroral phenomena.

In 1961 Dungey suggested that the north/south $\left(B_{z}\right)$ component of the interplanetary magnetic field (IMF) may have an influential effect on the ionospheric 
convection pattern. Since then a mass of experimental evidence has confirmed this to be the case (e.g. Cowley, 1982, and references therein). The IMF $B_{y}$ component also imposes a strong skewing force on the high-latitude convection pattern (e.g. Cowley, 1981) which results, within the northern hemisphere, in anti-sunward flow being dragged towards the morning sector for IMF $B_{y}$ positive and towards the evening sector for $B_{y}$ negative (e.g. Reiff and Burch, 1985), with an opposite variation produced within the southern hemisphere. This skewing force imposed on the ionosphere also results in the dawn-dusk displacement of the auroral oval, within the southern hemisphere, in the direction of the imposed $B_{y}$ component (Holzworth and Meng, 1984). Descriptions of the high-latitude convection pattern for a variety of interplanetary conditions, during steady-state conditions, have been produced from observations by magnetometers, spacecraft and ground-based radars (e.g. Friis-Christensen et al., 1985; Heppner and Maynard, 1987; Foster, 1983). Cowley and Lockwood (1992) presented a theoretical model to describe the various steady-state ionospheric convection pattern observations based on the cumulative effect of non-steady-state processes connected to the nightside and dayside auroral ionosphere. The response times ionosphere to changes in the IMF at the dayside magnetopause and therefore the magnetospheric convection has also been established (e.g. Etemadi et al., 1988; Todd et al., 1988; Greenwald et al., 1990; Lester et al., 1993) and is of the order of $15 \mathrm{~min}$ in the dawn/dusk meridian. An investigation of the high-latitude convection pattern, observed simultaneously in both hemispheres observed by high-frequency (HF) radars, can provide the opportunity to examine the time-dependent nature of the coupling between the solar wind, magnetosphere and ionosphere during a period of energy transfer throughout the solar wind-magnetosphere-ionosphere system.

Such a conjugate study undertaken during a period of substorm activity will provide valuable information concerning the mechanism of, and the ionospheric response to, the substorm process within opposite hemispheres and the control of such a process by the orientation and magnitude of the IMF. Also, the dynamic response of the high-latitude ionospheric convection to substorm unloading and its relative importance to the dayside driven ionospheric convection will provide information concerning the energy balance and transfer within the coupled magnetosphere-ionosphere system.

In this study we predominantly employ data from the Polar Anglo-American Conjugate Experiment (PACE; described in detail by Baker et al., 1989), both radars now form part of the Super Dual Auroral Radar Network (SuperDARN, Greenwald et al., 1995). The PACE system provides a nominal conjugate observation area in excess of $3 \times 10^{6} \mathrm{~km}$ (Dudeney et al., 1991), based on magnetic field line mapping by the AACGM field model. HF radars are excellent instruments for the study of conjugacy, by virtue of their very large fields of view. However, the locations from which the radars backscatter are a strong function of time of day and season, as the HF radio-wave propagation is strongly affected by the ambient ionospheric electron density (Milan et al., 1997). A degree of displaced conjugacy may thus result from any non-conjugacy in local ionospheric conductivity due to differences in e.g. solar illumination. Such non-conjugacies will minimise at equinox, although even then the displacement of the magnetic and geographic poles will introduce some interhemispheric differences. Thus the presence or absence of radar backscatter alone is not sufficient to indicate the level of conjugacy during an interval. Rather, the plasma flow must be characterised and any interhemispheric contrast quantified. In addition, such instrument-dependent effects are partially mitigated in the present study by the use of additional plasma flow data from two DMSP spacecraft.

In the present study we examine an example of interhemispheric contrast (non-conjugacy) in the ionospheric convection flow, observed by the PACE system, which can be attributed to a large-scale interhemispheric difference in the position of the convection reversal boundary and the MLT of the observing instrumentation. The location of this boundary in each hemisphere is suggested to be controlled by the IMF.

\section{Instrumentation}

The PACE system consisted of two poleward pointing HF backscatter radars, one located at Halley, Antarctica $\left(76^{\circ} \mathrm{S}, 27^{\circ} \mathrm{W}\right)$, and the other at Goose Bay, Labrador $\left(53^{\circ} \mathrm{N}, 60^{\circ} \mathrm{W}\right)$. Figure 1 illustrates the fields

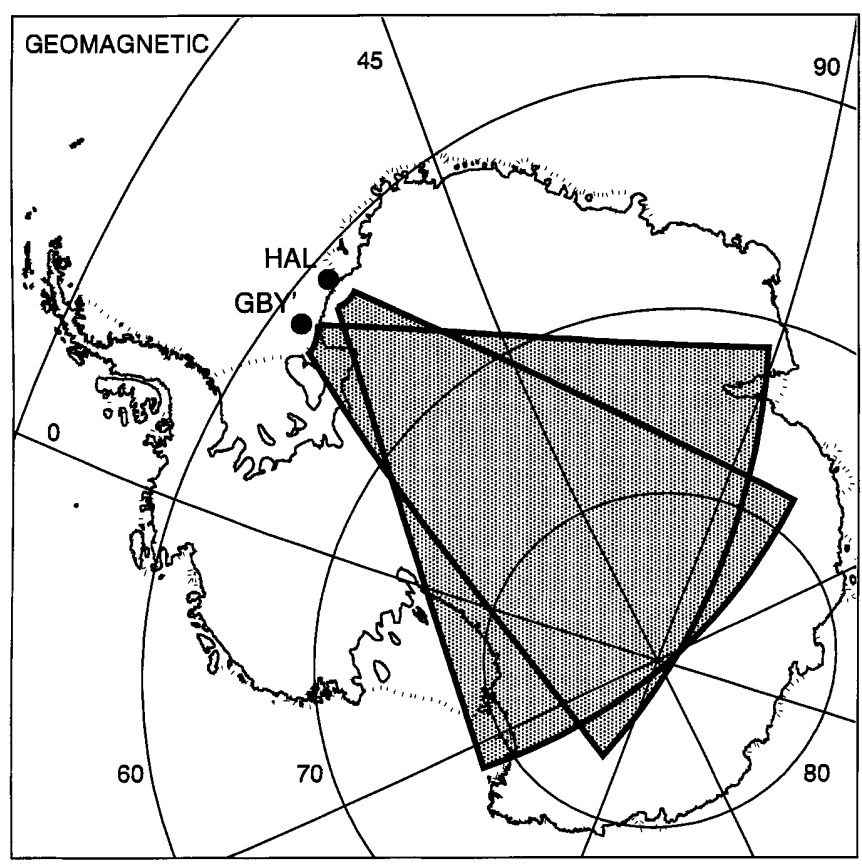

Fig. 1. Schematic of the PACE overlapping fields of view, comprising the antarctic radar at Halley (HAL) and the northern-hemisphere radar at Goose Bay (GBY). The northern-hemisphere radar has been mapped into the southern hemisphere using the PACE Geomagnetic Co-ordinate (AACGM) system 
of view of the two radars, with the northern-hemisphere radar (i.e. Goose Bay) mapped, using the AACGM coordinate system, into the southern hemisphere. Each radar is frequency agile within the range $8-20 \mathrm{MHz}$ and is therefore sensitive to ionospheric plasma irregularities with wavelengths between 10 and $30 \mathrm{~m}$. At the time of the case-study discussed here the radar system routinely measured the line-of-sight (1.o.s.) Doppler velocity for 50 range cells along 16 beam directions with a typical integration period of $6 \mathrm{~s}$, and therefore, the complete radar field of view is scanned in $96 \mathrm{~s}$. Each of the 16 narrow beams are stepped in azimuth by $3.24^{\circ}$ increments to form a full scan covering $52^{\circ}$, with each of the range cells being $45 \mathrm{~km}$ along the 1.o.s of the radar for Halley and $30 \mathrm{~km}$ for Goose Bay. The distance to the first range cell can be software controlled to provide samples up to $3000 \mathrm{~km}$ in range. For each of the beams and ranges a 17 lag complex auto-correlation function is determined, from which the radial Doppler velocity can be deduced, along with backscatter power and spectral width. The fields of view of the two radars have been arranged to provide a sizeable conjugate overlap following inversion employing the PACE geomagnetic co-ordinate system. A more complete description of the radar systems is given by Greenwald et al. (1985).

In the present study data are also presented for the cross-track ion velocity as measured by the sensors onboard DMSP satellites F10 and F11 (Greenspan et al., 1986). These data provide invaluable information as to the location of ionospheric flow reversals during each pass of the polar regions, which takes $\sim 1 / 4$ of the satellite orbital period of $102 \mathrm{~min}$. The ion flows perpendicular to the spacecraft are sampled 6 times per second for each component and the data averaged into 4-s bins providing an along-track resolution of $\sim 30 \mathrm{~km}$. The location of the flow reversals from the satellite data provides a representation of the auroral ionospheric convection pattern independent of the ground-based radar data.

\section{Observations}

An interval of PACE data from 4 March 1992, which is the focus of the present study, is illustrated in Fig. 2a. The top two panels depict the radial velocity measured by the Halley radar along beams 3 and 12, respectively, and the lower two panels the radial velocity data along beams 3 and 12 from the Goose Bay radar. The radar beams scan from west to east and are numbered 0 to 15 . Positive velocities represent a flow towards the radar and negative velocities flow away from the radar. The radar beams illustrated in Fig. 2 a were chosen to provide an insight into the possible plasma flow direction based entirely on the observed radial velocities. The large separation in azimuth of the two beams provides a sufficient difference in their look direction to provide an insight into whether the true plasma flow direction is sunward or anti-sunward i.e. flow towards (away from) the radar within the most easterly beam and flow away from (towards) the radar in the most westerly beam would indicate sunward (anti-sunward) for observations made within the evening sector for both radars. However, examination of the full spatial maps (not shown) is required to provide a better, but not unambiguous, understanding of the large-scale flow features. Figure 2b illustrates the IMF $B_{z}$ (upper panel) and IMF $B_{y}$ (middle panel) components measured by the IMP 8 satellite at position defined in GSM coordinates $X, Y$ and $Z$ of approximately $34.5,2.0$ and $19.5 \mathrm{Re}$, respectively, during this interval. The IMP 8 magnetic field observations presented have been shifted to later times by 8 min to provide an approximate delay between the spacecraft observation point and interaction at the subsolar magnetopause (Lester et al., 1993). The lower trace of Fig. $2 b$ depicts a 15 -min running mean of the ratio of $B_{y}$ and $B_{z}$, where points for which the absolute value of $B_{z}$ was less than $1 \mathrm{nT}$ were eliminated from the calculation of this ratio. The vertical dashed lines, in both Fig. 2a and b indicate times at which enhanced $\mathrm{Pi} 2$ wave activity was observed in magnetic field measurements made by the SAMNET array (Yeoman et al., 1990), and the dashed-dotteddotted lines illustrate times when the $Z$-component of the IMF undergoes a southward turn. The dasheddotted line at $\sim 1945$ UT illustrates the observation time of a second interval of enhanced Pi2 wave activity observed at the higher-latitude IMAGE stations (Lühr et al., 1984) of Bear Island and Hopen. The interval presented in Fig. 2a (radar data) and Fig. 2b (IMF observations) has been further subdivided into three periods which are characterised by the orientation of the IMF and the spatial structure of the HF backscatter observed by both Halley and Goose Bay.

\section{Period 1: 1828-1920 UT}

The start of this period is defined by the southward turn in the IMF, i.e. $B_{z}<0$. Note that in the following sections the timing of IMF variations is made with reference to the time-shifted IMP 8 satellite data illustrated in Fig. 2b. Approximately $15 \mathrm{~min}$ after the southward turn of the IMF simultaneous enhancements in the plasma velocity are observed at both Halley (Beam $3 ; 74^{\circ} \mathrm{S}-76^{\circ} \mathrm{S}$ AACGM latitude) and Goose Bay (Beam $12 ; 72^{\circ} \mathrm{N}-73^{\circ} \mathrm{N}$ AACGM latitude). The small flow responses in beam 12 of Halley and beam 3 of Goose Bay imply an $\mathbf{E}$. $\mathbf{B}$ drift which is perpendicular to the radar look direction. Examination of full spatial maps (not shown here) confirm that this flow response is associated with sunward ionospheric plasma convection. This result itself would suggest that the flow pattern in opposite hemispheres on a large scale are similar, although the specific direction and magnitude of the flow, which cannot be unambiguously determined from this data set, may not be entirely consistent. The auroral feature in the southern hemisphere is displaced approximately $3^{\circ}$ (six radar range gates) polewards of that in the northern hemisphere. This suggests displaced conjugate observations during a period of southward IMF. We 


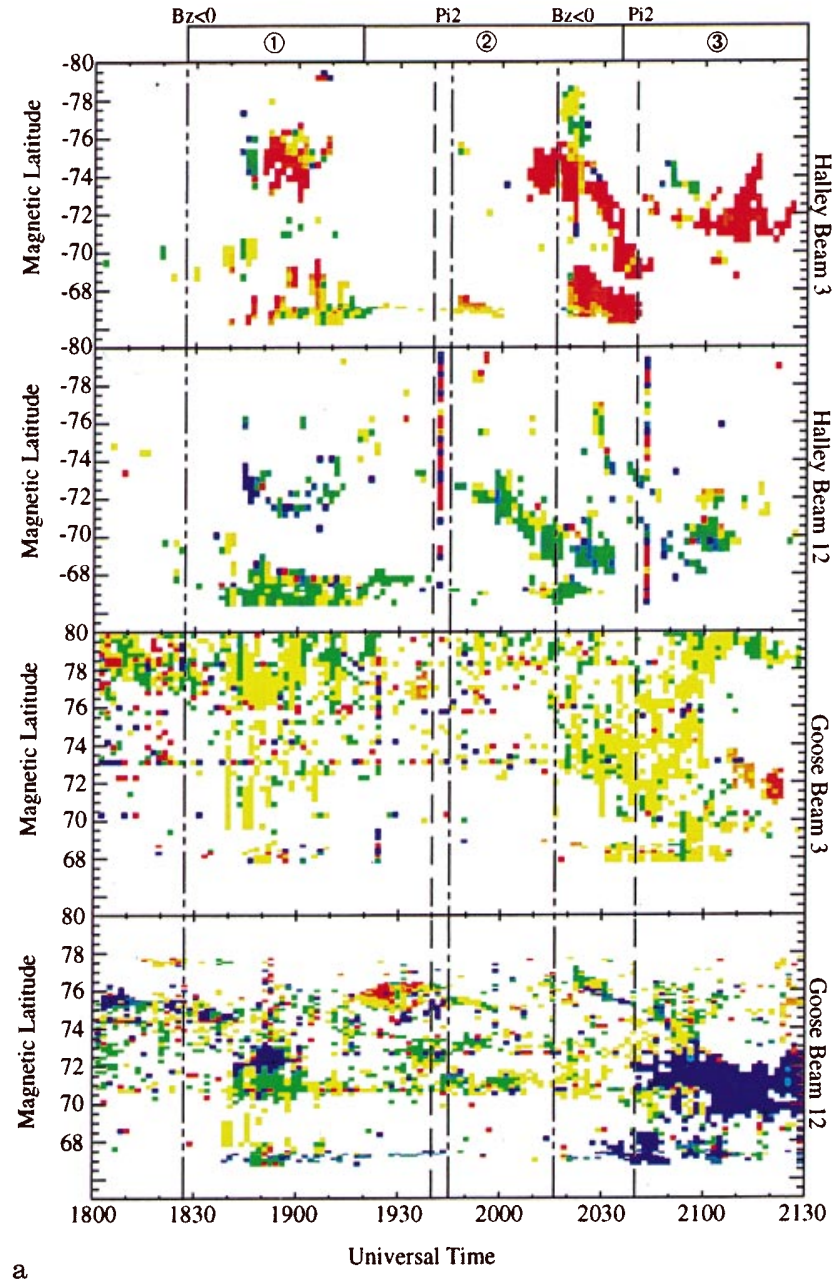

Fig. 2. a Line-of-sight Doppler velocity as a function of AACGM latitude for beams 3 and 12 of Halley in the southern hemisphere (upper two panels) and Goose Bay in the northern hemisphere (lower two panels) from March 1992. b The upper two panels depict the IMF $B_{z}$ and $B_{y}$ components with an 8-min time-shift to account for transit time of the feature to the subsolar magnetopause (e.g. Lester et al.,

note at this point that the magnitude of the ratio of $B_{y}$ to $B_{z}$ is of order 0.5 . The implications of this observation will be discussed in the context of an auroral convection response in following sections.

Further evidence of the field line linkage between the northern- and southern-hemisphere radar fields of view is provided by the observations of a Pc5 (ULF) wave in the 1.o.s. data from the two radars. This is illustrated most clearly in data from beam 3 of the Halley radar (upper panel of Fig. 3) and beam 12 Goose bay radar (centre panel of Fig. 3). The H-component magnetic field perturbation, band-pass filtered between 150 and $1000 \mathrm{~s}$, from the Greenland magnetometer station at Frederikshab (Friis-Christensen et al., 1985) is depicted in the lower panel of Fig. 3. The Pc5 wave in the magnetometer data amplitude has a maximum around $68^{\circ} \mathrm{N}$ Geomagnetic, the latitude of the two most equatorward Greenland-East stations, and decreases with increasing latitude. The wave signature observed in

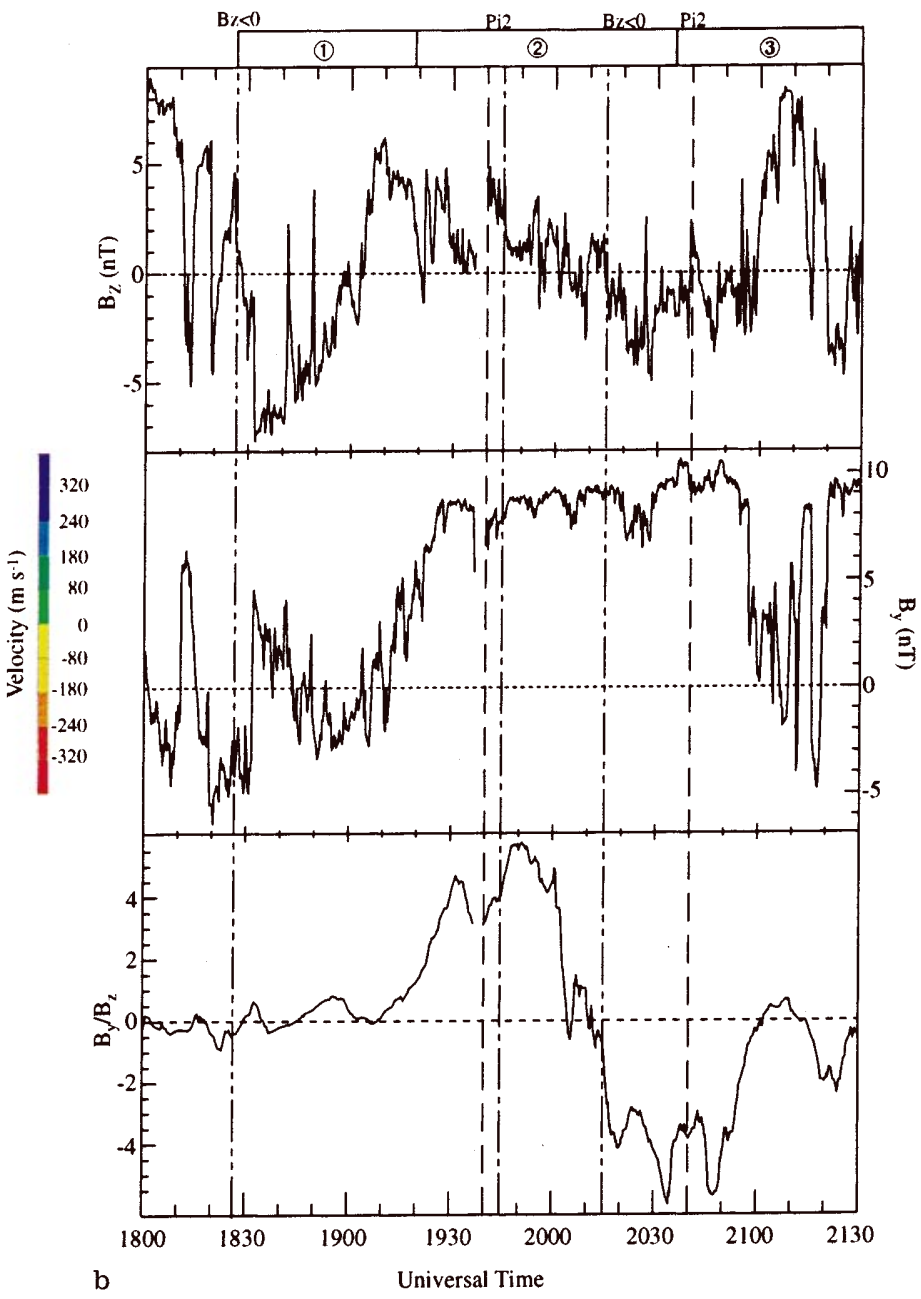

1993). The lower panel illustrates a 15 -min running mean of the ratio of IMF $B_{y}$ and $B_{z}$ (see text for details). Both $\mathbf{a}$ and $\mathbf{b}$ have been subdivided into three periods based on the IMF conditions and flow response observed by the HF radars. The vertical dashed and dash-dot lines mark the times $\mathrm{Pi} 2$ activity and the dash-dot-dot lines times when $B_{z}$ turns southwards

both of the HF radars is of a very similar period to that illustrated in magnetometer data, such a Pc5 signature is indicative of a field-guided Alfvén wave causing a closed magnetospheric field line to resonate, and thus the wave is a good indicator of conjugacy. The strongest wave signature in the radar data is again observed somewhat more polewards in the southern hemisphere than the northern hemisphere, although there is less displacement than observed in the convection features at higher latitudes. Although an interesting observation in itself, an examination of the wave characteristics will not form a part of this study; it is however confirmation of nearconjugate observations by the two radars during this period. The observation of the Pc5 wave also confirms that the magnetic field line linkage is well represented by the AACGM co-ordinate system at latitudes of $\sim 68^{\circ}$, further suggesting that the feature observed around $74^{\circ}$, at this time is a genuine observation of displaced conjugacy. 


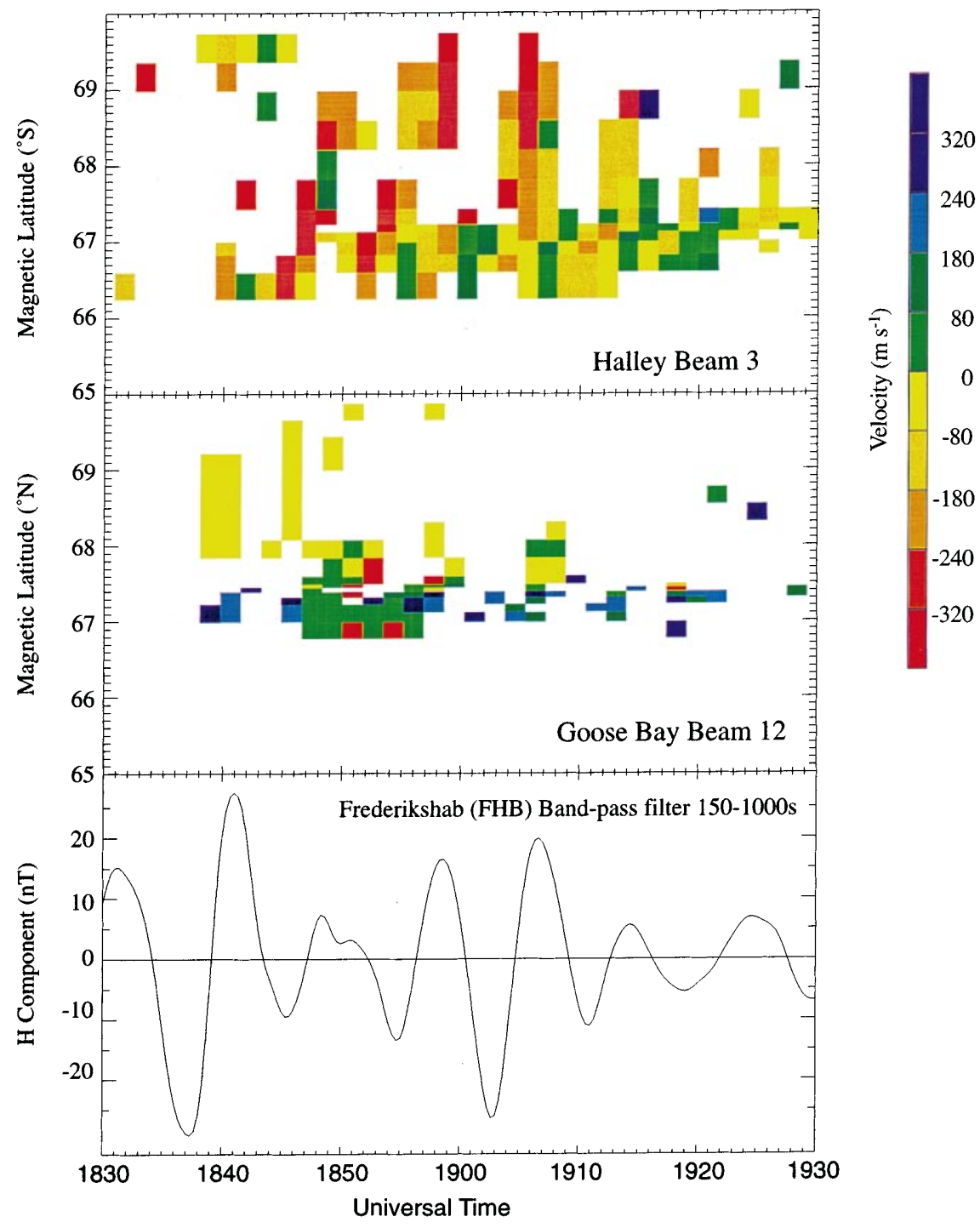

Fig. 3. The top panel depicts the line-of-sight Doppler velocity as a function of AACGM latitude and time from Halley beam 3 and the middle panel the corresponding data from the Goose Bay radar for beam 12. The lower panel depicts $\mathrm{H}$-component magnetic field perturbations, band-pass filtered with in the range of $150-1000 \mathrm{~s}$, from the Greenland magnetometer station at Frederikshab

\section{Period 2: 1920-2030 UT}

Period 2 is characterised by an interval of predominantly northward IMF (ranging from $\sim 0$ to $5 \mathrm{nT}$ ) with a strong IMF $B_{y}$ component of $\sim 10$ nT (i.e. $\left|\mathbf{B}_{\mathbf{y}}\right| \gg\left|\mathbf{B}_{\mathbf{x}}\right|$ and $B_{y} / B_{z} \sim 4$, Fig. $2 \mathrm{~b}$, bottom panel). The scatter observed by the PACE radars during this period, in contrast to the previous period, illustrates a strong interhemispheric contrast in the ionospheric plasma convection. Data from the Halley radar between 1920 and 1940 UT, presented in Fig. 2a, illustrate a relatively quiescent period during which little ionospheric backscatter is observed. The data presented from beam 12 of the Goose radar illustrate a region of ionospheric scatter, at approximately $1930 \mathrm{UT}$ and $76^{\circ} \mathrm{N}$, which initially is characterised by an l.o.s flow away from the radar and later by 1.o.s flow towards the radar. At this time the SAMNET and IMAGE magnetometer arrays are located within the pre-midnight sector and are therefore well placed to observe $\mathrm{Pi} 2$ and substorm activity. At 1940 UT a burst of Pi2 activity is observed in the SAMNET magnetic data records, with a further increase in Pi2 wave activity around 1945 UT observed in the high-latitude IMAGE stations located at Bear Island and Hopen. Approximately $5 \mathrm{~min}$ after the increase in the Pi2 magnetic wave activity a response is observed at Halley (Beam 12; $73^{\circ} \mathrm{S}$ ) in the form of an increase in the area from which backscatter is returned. The exact location of the break-up region associated with the Pi2 activity is difficult to determine from the magnetic records but it is situated east of the IMAGE and SAMNET array consistent with the time-delay between Pi2 observation and radar backscatter enhancement along with an associated westward expansion speed around $1.5 \mathrm{~km} \mathrm{~s}^{-1}$ (Yeoman and Pinnock, 1996). This spatially coherent area of backscatter appears to propagate equatorwards with time. A similar region of scatter is observed around 2005 UT in Beam $3\left(\sim 76^{\circ} \mathrm{S}\right)$. The upper two panels of Fig. 4 depict two full spatial maps of the Halley data in AACGM co-ordinates. The radar scans west to east through 16 beams which are numbered 0 to 15 . This Figure illustrates the apparent sunward and equatorward propagation of the region of enhanced ionospheric plasma flow, i.e. at 1956 UT the 
Halley

$195638 \mathrm{~s}(64)$

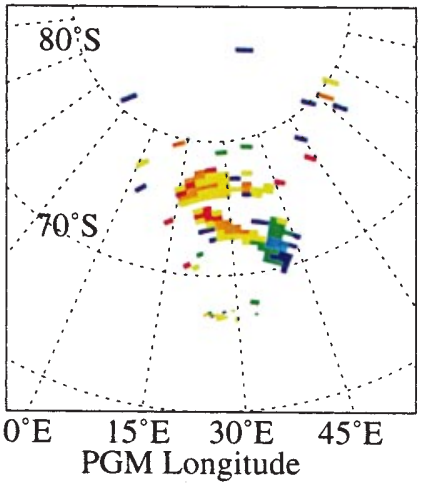

201519 s (64)

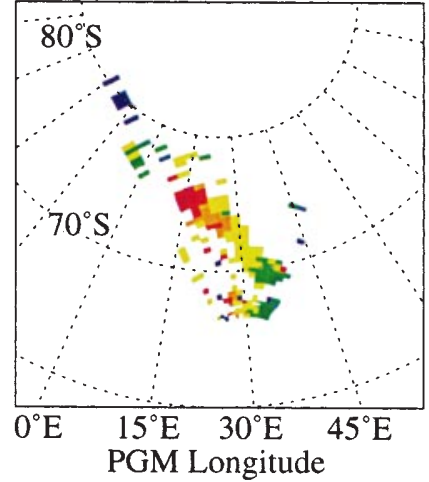

Simulation of Halley data

smsep $=300.0:$ lagfr $=3900.0$

rot. angle $=9.00^{\circ}$ : flow vel $=375.00 \mathrm{~m} \mathrm{~s}^{-1}$

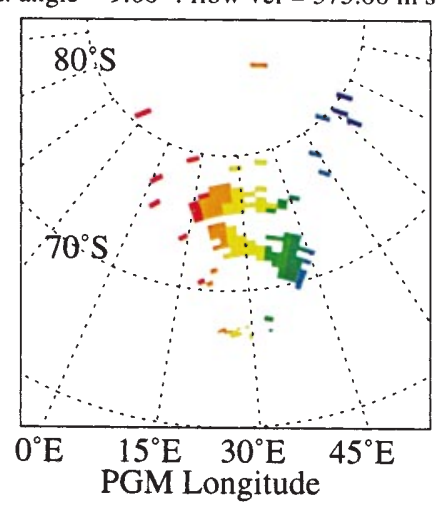

smsep $=300.0:$ lagfr $=3900.0$

rot. angle $=16.00^{\circ}:$ flow vel $=325.00 \mathrm{~m} \mathrm{~s}^{-1}$

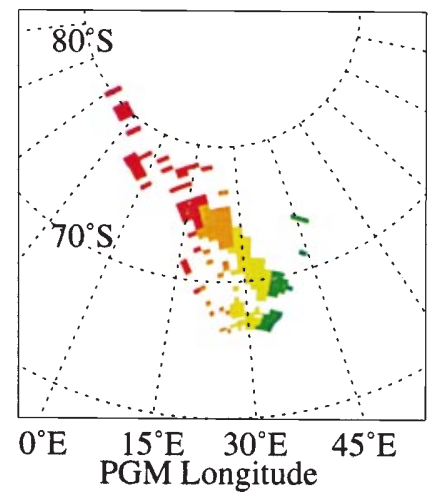

320

240

160

80

0

$-80$

$-160$

$-240$

$-320$

Goose Bay
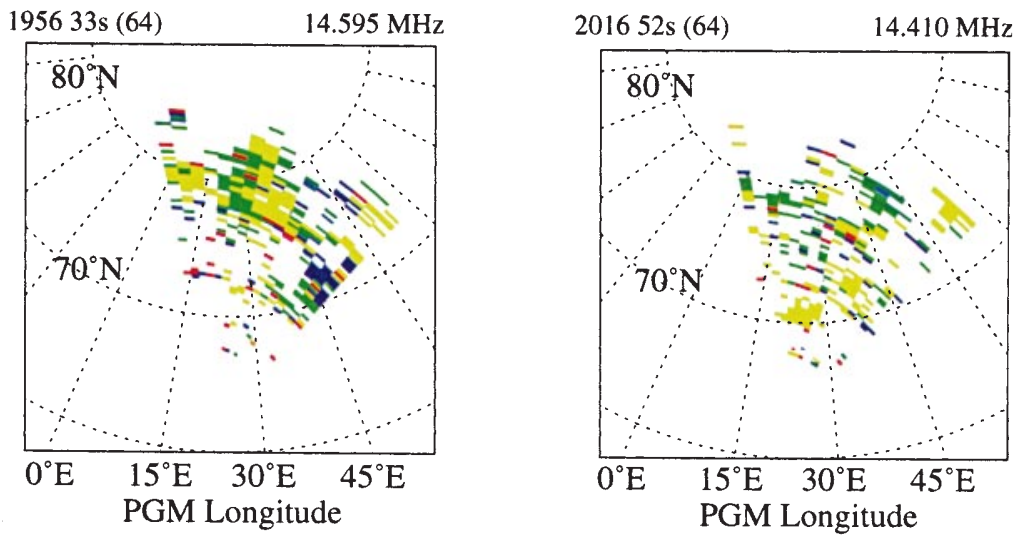

Fig. 4. The top two panels depict 16 beam scans of Doppler velocities measured by the Halley radar system in the southern hemisphere at 1956 and 2015 UT. The middle two panels illustrate a model fit to the Halley data presented in the upper panels (see text for the model details). The lower two panels show the Goose Bay data from the northern hemisphere illustrating the difference in the scatter observed at nominally conjugate sites

right-hand side of the field of view (beams 12 to 15) illustrates an enhancement in the 1.o.s flow around $70^{\circ} \mathrm{S}$, by 2016 UT this region has expanded equatorward to $\sim 65^{\circ} \mathrm{S}$. The centre two panels of Fig. 4 depict fitted data to the spatial maps presented in the upper two panels. A model fit to the radar l.o.s velocity data has been obtained by firstly assuming that the flow is uniform across the entire field of view. Then both the direction and magnitude of the flow are varied such to minimise the difference between the modelled and observational data. Modelled data is both fitted and plotted only in range cells where actual backscatter was recorded. The area of scatter associated with the two patterns was found, by this technique, to be best described by a sunward flow of $\sim 350 \mathrm{~m} \mathrm{~s}^{-1}$ aligned at an angle of between $8^{\circ}$ and $15^{\circ}$ to the AACGM latitude contours. The apparent equatorward motion of the backscatter at Halley (Fig. 2a) may be the result of the motion of the radar field of view, in AACGM co-ordinates, with respect to this flow channel. Whereas, the east-west (sunward) propagation of the flow enhancement (i.e. scatter is observed in beam 12 before beam 3, see Fig. 2a) is most probably associated with the westward expansion of nightside-driven ionospheric convection 
associated with the substorm expansion indicated by the Pi2 activity at between 1940 and 1945 UT, i.e. the region of flow enhancement can be seen to expand westwards across the field of view within a region where backscatter is already present (Fig. 4). The Goose Bay data at this time, however, do not illustrate a coherent area of scatter which can be readily associated with the backscatter observed by Halley during the interval. This is not to say there is no radar backscatter in the Goose Bay field of view, just that there is a period during which there is strong interhemispheric contrast in the structure of the scatter observed. The lower two panels of Fig. 4 illustrate the spatial maps for the same interval as the Halley data. These clearly illustrate that scatter is present although there is no evidence of a simple flow structure within the radar field of view.

\section{Period 3: 2030-2200 UT}

At $\sim 2019$ UT the IMF turns southwards again and remains negative or close to zero until $\sim 2100 \mathrm{UT}, B_{y}$ also remains positive and large until $\sim 2100 \mathrm{UT}$. There is an increase in the $\mathrm{Pi} 2$ wave activity observed in data at some of the SAMNET stations around 2040 UT. Shortly after the increase in $\mathrm{Pi} 2$ wave activity a considerable enhancement is observed in the radial velocities measured by Halley (Beam 3) and Goose (Beam 12). Again, there are no substantial velocities measured in Beams 12 and 3 of Halley and Goose, respectively. The ionospheric convection flow at this time can be described by sunward (east-west) motion of plasma, which appears itself to propagate westward (i.e. flow enhancements are observed in the most easterly beams prior to those in the west). This region of fast sunward flow may be associated with the substorm break-up and subsequent increase in the auroral convection pattern through a nightside-driven convection enhancement [e.g. following the model of Cowley and Lockwood (1992)], as was observed in the Halley radar during the previous period. During this period, however, the scatter is, in contrast to the previous period, reasonably conjugate with a displacement of less than $2^{\circ}$ in latitude. This would suggest that during initial stages of this period the interhemispheric convection flow is more symmetric. The ratio of $B_{y}$ to $B_{z}$ is approximately -4 and reduces to nearly zero around 2110 UT. Therefore these data support the hypothesis that this ratio controls the magnitude of the skewing of the ionospheric flow pattern, providing more conjugate observations during a period when this value is lower, i.e. after $\sim 2110$ UT. In this case, however, a return to a more symmetric pattern is obvious before 2110 UT. A possible explanation for the return to a more symmetric convection before the large-scale reduction in $B_{y}$ will be discussed in the following section.

\section{Discussion}

Each of the periods outlined in the previous section will be discussed with reference to the model proposed by
Cowley and Lockwood (1992), which describes the auroral ionospheric convection pattern in terms of two time-variant driving mechanisms associated with magnetic field line merging at the dayside magnetopause and within the nightside magnetotail. The convection patterns presented here are not intended to represent in detail the actual ionospheric convection pattern, but provide a schematic view of a possible pattern based on the average prevailing IMF conditions.

\section{Period 1}

Figure 5a depicts a theoretical symmetric two-cell convection driven by merging at the dayside magnetopause. The contours represent the ionospheric flow stream lines whereas the circle depicts the boundary between open and closed magnetic field lines. The dashed portion of the open/closed field line boundary illustrates the merging gap, i.e. the region which maps to a site of magnetic reconnection, providing either new open magnetic flux on the dayside or the closure of open magnetic field lines on the nightside. This simple picture of the ionospheric convection is consistent with the horizontal component of the cross-track ion velocity
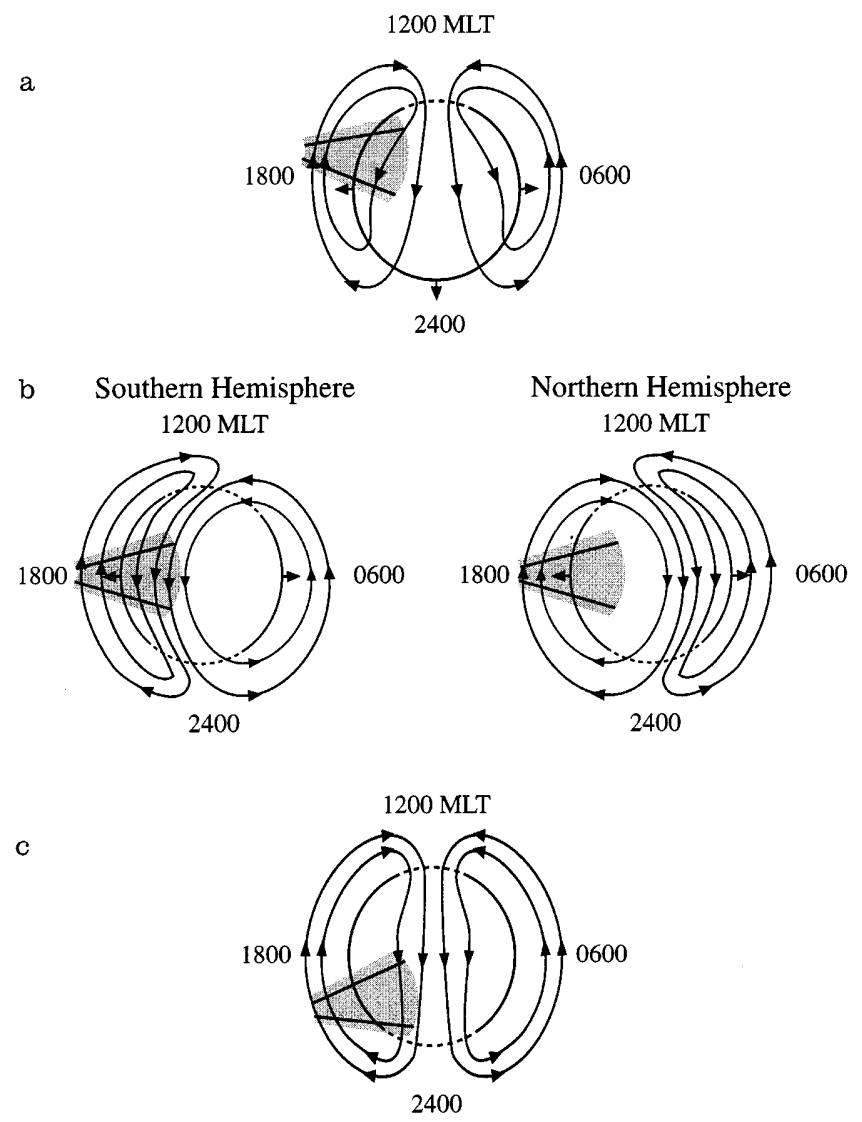

Fig. 5. a A possible ionospheric flow pattern for period 1 of the study interval (see text for details). The solid lines represent the flow stream lines and the circle the polar cap boundary, with the dashed lines indicating the merging gaps, or regions of creation or destruction of open flux. b A proposed ionospheric convection flow for period 2. c The ionospheric flow suggested for the later part of period 3 
recorded by the DMSP satellites in this period during passes of the southern hemispheres and the northern hemisphere presented in Fig. 6a. In both the southern and northern hemisphere ion flow is observed in an antisunward direction within the centre of the satellite pass and in a sunward direction towards the edges, i.e. below $\sim 75^{\circ}$ AACGM. In each of the satellite passes presented in Fig. 6a only the horizontal component of the ion flow perpendicular to the satellite track is depicted. This provides an overview of the regions of sunward and anti-sunward ion drifts for the periods presented. This interpretation of the flow pattern is entirely consistent with the region of sunward flow observed in both hemispheres by the Halley and Goose Bay HF radars. The symmetric nature of the flow pattern provides the necessary geometry to ensure the radar backscatter scatter is approximately conjugate. Any degree of displaced conjugacy may be due to magnetospheric effects or local ionospheric conditions, as discussed in Sect. 1. We also note that the response time of the ionospheric flows to the southward turning is $\sim 15 \mathrm{~min}$, which is entirely consistent with that suggested by a number of other authors (i.e. Etemadi et al., 1988; Todd et al., 1988; Yeoman and Pinnock, 1996) for the MLT of the present period. Thus, we may positively associate the ionospheric flow response with the activation of magnetic field line merging at the dayside magnetopause, a process observed simultaneously in opposite hemispheres during the period under study.

\section{Period 2}

Figure $5 \mathrm{~b}$ depicts a convection pattern which we suggest may explain the observations made by the radar systems in opposite hemispheres. Both the southern and northern hemisphere patterns are presented here as the pattern is strongly asymmetric as a direct consequence of the orientation of the IMF. The strong $B_{y}$ component during this period (i.e. positive $B_{y}$ where $B_{y} / B_{z} \sim 4$ ) results in the formation of a crescent shaped dusk (dawn) sector in the southern (northern) hemisphere and a round-shaped cell in the dawn (dusk) sector of the southern (northern) hemisphere. These patterns are a

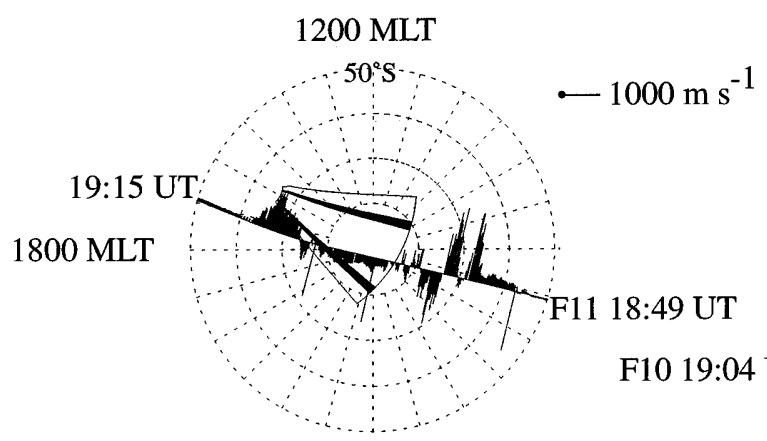

0000 MLT

\section{Northern Hemisphere}

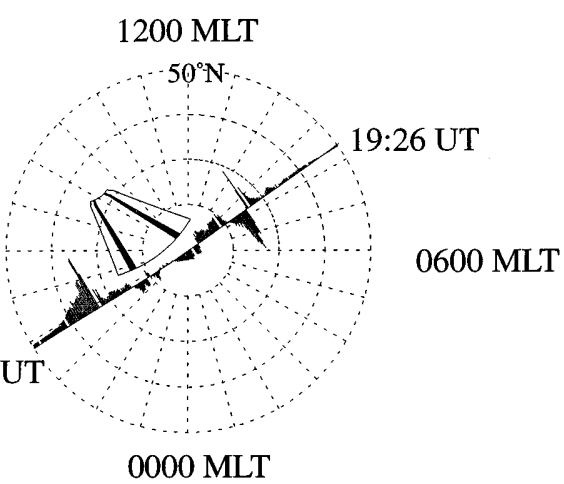

b

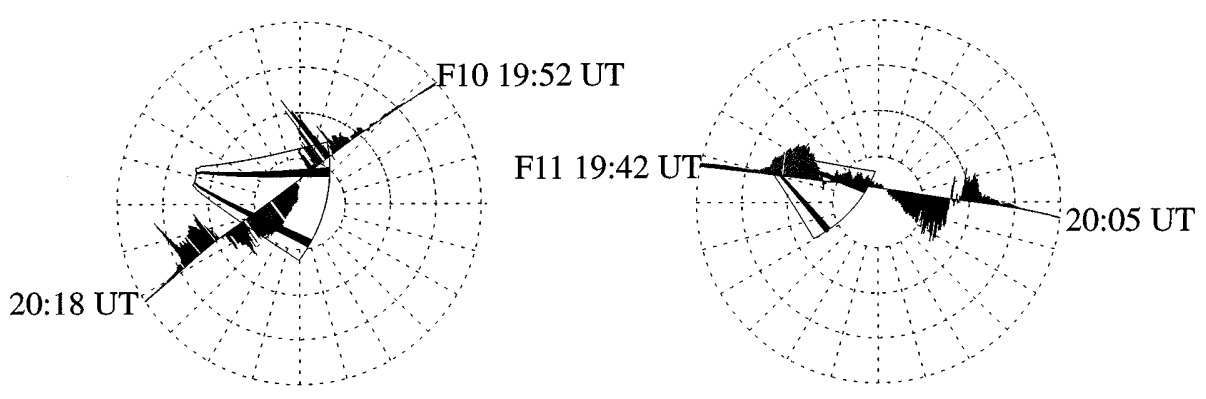

c

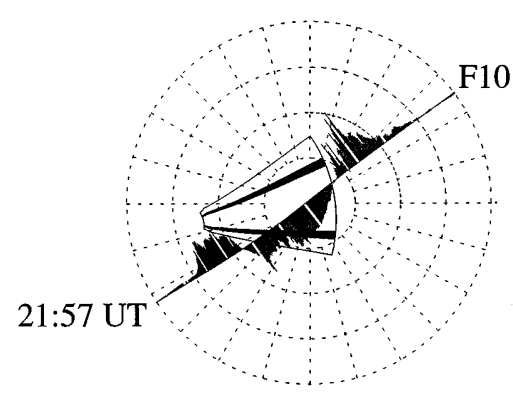

F10 21:31 UT

F11 21:22 UT

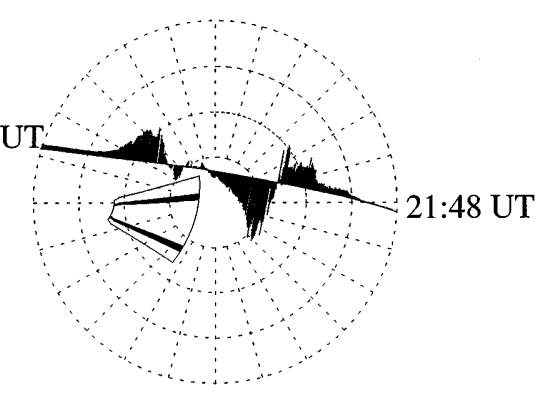

Fig. 6a-c The DMSP crosstrack ion velocities from the satellites F11 and F10. The data periods illustrated correspond directly to the intervals for which the ionospheric convection schematics were presented in Fig. 5. The fields of view of the Halley and Goose Bay radars are illustrated, with beams 3 and 12, depicted in Fig. 2a, marked in black 
consistent with the statistical observations deduced from the Goose Bay radar observations by Ruohoniemi and Greenwald (1996) and those determined by AMIE (Lu et al., 1994). The form of the convection pattern presented in Fig. 5b is also entirely consistent with that suggested by the DMSP observations for period 2 (see Fig. 6b). The southern-hemisphere pass illustrates a flow reversal, from sunward to anti-sunward, at $\sim 72^{\circ} \mathrm{S}$ and $1930 \mathrm{MLT}$ and $\sim 90^{\circ} \mathrm{S}$ at $1200 \mathrm{MLT}$; also, the radar data from beam 3 of Halley presented in Fig. 2a illustrate a reversal in the flow around $76^{\circ} \mathrm{S}$ at 2020 UT (i.e. the time of the satellite pass). The satellite pass within the northern-hemisphere flow reversals are observed around $\sim 90^{\circ} \mathrm{N}$ at $1800 \mathrm{MLT}$ and $75^{\circ} \mathrm{N}$ at 0600 MLT. The study by Lu et al. (1994) employing AMIE and work by Ruohoniemi and Greenwald (1996) with the Goose HF radar have indicated that this form of the ionospheric convection pattern was observed for both positive and negative $B_{z}$ during periods in which $B_{y}$ dominated $B_{z}$.

Possibly the most important aspect of the suggested convection patterns is the existence of a strong flow shear within the field of view of the southern-hemisphere radar but not within that of the northern-hemisphere radar. A direct consequence of the flow shear is that a field-aligned current (FAC) is required in order to maintain current continuity across the boundary between the two flow directions. Furthermore, this FAC system will provide an enhanced possibility for the excitation of the plasma instabilities required for the growth of the plasma waves critical to $\mathrm{HF}$ radar observations [see reviews of F-region irregularities by Kelley (1989) and Tsunoda (1988)]. Therefore, it follows that the excitation of plasma instabilities and therefore scattering targets is more likely within the field of view of the southern hemisphere rather than the northern hemisphere radar system at this time. The asymmetry in the potential for irregularity generation would result in the preferential observation of any enhancements in the plasma convection velocity to be observed within the southern hemisphere. The data presented in Figs. 2a and 4 do indeed illustrate this point, with a flow enhancement associated with a substorm expansion at 1940 UT, observed by the Halley radar system between 2000 and $2030 \mathrm{UT}$ and within the AACGM latitude range $68^{\circ} \mathrm{S}$ and $76^{\circ} \mathrm{S}$, which is close to the latitude flow reversal observed by DMSP (see Fig. 5b). During the same period however, the Goose Bay system does not observe a spatially coherent area of backscatter, which may be associated with the feature observed by Halley and the DMSP data (see Fig. 5b) suggesting that the radar field of view is located within a more quiescent region of sunward ionospheric convection, i.e. the flow reversal observed by DMSP in the relevant time-sector is poleward of the radar field of view.

\section{Period 3}

The scatter observed within the field of view of both radars during this period can be described by an east- west (sunward) plasma flow, and is probably associated with the substorm expansion which occurred $\sim 10 \mathrm{~min}$ earlier. During this period the region of backscatter observed in opposite hemispheres is relatively conjugate, with enhancements in the radar backscatter and flow velocity initially being observed around 2040 UT at AACGM latitudes of $72^{\circ} \mathrm{N}$ and $74^{\circ} \mathrm{S}$ for Goose Bay and Halley, respectively. The ratio of IMF $B_{y}$ to $B_{z}$ is $\sim-4$ at the start of this period, a magnitude which is comparable with that observed during the previous period dominated by non-conjugate observations, returning to a value close to zero after $\sim 2100$ UT (see Fig. 2a, b). Between approximately 2100 and 2110 UT the ionospheric flow probably undergoes a period of reorganisation to a more symmetric form as $B_{y}$ reduces in magnitude. Figure 5c illustrates one such possible configuration of the auroral ionospheric stream lines which is supported by the DMSP ion drift velocity data presented in Fig. 6c. An anti-sunward/sunward convection reversal is observed around $75^{\circ} \mathrm{N}$ in both the evening and morning sectors of the northern hemisphere and at $\sim 72^{\circ} \mathrm{S}$ and $\sim 80^{\circ} \mathrm{S}$ in the southern hemisphere within the evening and morning sectors, respectively. The northern-hemisphere satellite data suggest a flow pattern is in transition from a pattern described by $b$, for the northern hemisphere, and our final pattern schematically illustrated in Fig. 5c.

Recently, Wing et al. (1995) made comparisons between 11 years of GOES-6 and GOES-7 magnetometer data and the $y$-component of the IMF, the results indicated a correlation between the IMF and GOES measurements of 0.61 at local noon and 0.50 at local midnight, with a value below 0.2 at other times. This suggests that as observations move from local noon towards local midnight the relative importance of the $B_{y}$ skew on the magnetospheric configuration becomes reduced, i.e. nightside-driven convection observed closer to local midnight is less affected by the magnitude of the IMF $y$-component than those observed away from local midnight. Thus, a return to somewhat more conjugate observation prior to the $B_{y}$ to $B_{z}$ ratio returning to a level comparable to that of period 1 (i.e. between 2030 and 2100 UT), can be interpreted as a direct result of the observations being made some $2 \mathrm{~h}$ closer to local magnetic midnight than during the previous period, where the intrusion of the IMF $B_{y}$ into the magnetospheric cavity and hence its effectiveness in producing substantial skew on any substorm intensification may be lessened.

Rodger et al. (1984) described the asymmetric location in MLT of the Harang discontinuity as a function of IMF $B_{y}$, with its location within the northern hemisphere skewed $\sim 2 \mathrm{~h}$ westwards and the southern hemisphere $\sim 2 \mathrm{~h}$ eastwards, for an IMF $y$-component of $\sim 8 \mathrm{nT}$. There is a small reduction in the area of radar backscatter between 2040 and 2100 UT at Halley in contrast to the increase at Goose Bay, an observation which may result directly from the distance of the breakup region, from the radar field of view (i.e. the closer to the break-up region the greater the flow enhancement that may be observed if the flow enhancement and 
irregularity generation is relatively localised). If we postulate a motion of the substorm break-up region in a similar fashion to Rodger et al. (1984), then the reduction in the radar backscatter at Halley and increase at Goose Bay between 2040 and 2100 UT, illustrated in Fig. 2a, may be tentatively interpreted as a direct result of the proximity of the two stations to the break-up region, with the northern-hemisphere radar being some $4 \mathrm{~h}$ closer and hence influenced more strongly by the substorm-driven convection and associated processes than its southern-hemisphere counterpart.

\section{Conclusions}

The results of the present study suggest that within the evening sector the dominant controlling parameter on the variability of interhemispheric contrast in the observed ionospheric flow is the orientation of the IMF, specifically the ratio $B_{y}$ to $B_{z}$. A strong asymmetry in the ionospheric convection pattern in opposite hemispheres can be attributed to a strong and positive $B_{y}$ component as suggested by a previous statistical study of the ionospheric convection by Lu et al. (1994) even for flow driven by the substorm expansion phase. From the results of this study it is suggested that the primary mechanism for the resulting non-conjugacy is the interhemispheric difference in the position of the FAC system, associated with the convection reversal boundary, with respect to the radar field of view (i.e. the location of the region 1 currents within the evening sector). During periods when appropriate statistical ionospheric convection patterns and DMSP ion drift measurements suggest a flow reversal, and therefore an FAC system, to be present in the field of view of both radars the interhemispheric contrast in the HF radar backscatter minimised, i.e. during periods 1 and the latter part of 3 (see Fig. 2a). The ratio of IMF $B_{y}$ to $B_{z}$ is less than 1 for the majority of these somewhat conjugate periods. During period 2, when the ratio of IMF $B_{y}$ to $B_{z}$ is generally greater than 1 , there is considerable asymmetry in the auroral ionospheric convection pattern observed. Both the DMSP data and models of the ionospheric flow suggest asymmetric flow patterns, resulting in a considerable variation in the location of the flow reversal boundary, and hence the FAC system, within evening sector in opposite hemispheres. This asymmetry in the location of the FAC ultimately results in the maximisation of interhemispheric contrast in the ionospheric flow enhancements observed in response to a substorm expansion by the radar system. Many studies (e.g. Friis-Christensen et al., 1985; Heppner and Maynard, 1987; Foster, 1983; Lu et al. 1994, Ruohoniemi and Greenwald, 1996) have illustrated a strong link between the form of the ionospheric convection pattern and the orientation and magnitude of the IMF, hence so should the level of conjugacy of the radar backscatter observed. This is borne out by the results of the present study, with the magnitude of the ratio of IMF $B_{y}$ to $B_{z}$ having been found to be closely linked to the level of interhemispheric contrast, with conjugate observations predominantly made when $\left|B_{y} / B_{z}\right| \leq 1$ and non-conjugate observations when $\left|B_{y} / B_{z}\right| \geq 1$. However, there is some evidence of conjugate observations during the beginning of period 3 (i.e. see Fig. 2a, 2040-2100 UT), when the magnitude of ratio of the IMF $B_{y}$ to $B_{z}$ remains around 4 when we might expect from our initial examination of period 2 considerable asymmetry in the interhemispheric convection flow patterns and therefore the non-conjugacy of any HF radar backscatter. This is however not the case, possibly as a result of the combination of the observations being made closer to local magnetic midnight during this final period, and therefore more controlled by flow enhancements resulting from substorm expansion, where the effect of the IMF $B_{y}$ component due to its entry into the magnetosphere is weakened (Wing et al., 1995). This will have the effect of reducing the level of asymmetry in the flow pattern imposed by the IMF $B_{y}$ component. There is, however, some evidence of a local time displacement of the location of the substorm break-up region in the radar data, which at the time of the observation is undoubtedly the source of the nightside ionospheric driving mechanism.

The present study has demonstrated that conjugate ionospheric convection, observed by HF radars, is a complex function of MLT, the magnitude of IMF $B_{y}$ and $B_{z}$ and substorm activity. The detailed behaviour of these conjugate observations may only really be answered through a large statistical analysis of observations by HF radars in both hemispheres for a diverse combinations of IMF orientations and magnitude and levels of substrom activity. This is a question which should be answerable with the aid of the SuperDARN radar network (Greenwald et al., 1995) being developed in both the northern and southern hemispheres.

Acknowledgements. The authors would like to thank S. E. Milan for providing much of the software used in analysis of the HF radar data, the NASA/GSFC IMP 8 magnetic field processing team for providing the IMP 8 IMF data and the Danish Meterological Institute for providing Greenland magnetometer data. B. A. Shand was supported by NERC grant GST/02/119.

Topical Editor D. Alcaydé thanks J.-P. Villain and another referee for their help in evaluating this paper.

\section{References}

Baker, K. B., and S. Wing, A new magnetic co-ordinate system for conjugate studies at high latitudes, J. Geophys. Res., 94, 91399143, 1989.

Baker, K. B., R. A. Greenwald, J. M. Ruohoniemi, J. R. Dudeney, M. J. Pinnock, N. Mattin, and J. M. Leonard, PACE-the polar Anglo-American conjugate experiment, EOS, 70, 785-799, 1989.

Cowley, S. W. H., Magnetospheric asymmetries associated with the Y-component of the IMF, Planet Space Sci., 29, 79-96, 1981.

Cowley, S. W. H., The cause of convection in the Earth's magnetosphere: a review of developments during the IMS, $J$. Geophys. Res., 20, 531-565, 1982.

Cowley, S. W. H., and M. Lockwood, Excitation and decay of solar wind-driven flows in the magnetosphere-ionosphere system, Ann. Geophysicae, 10, 103-115, 1992.

Dudeney, J. R., A. S. Rodger, M. Pinnock, J. M. Ruohoniemi, K. B. Baker, and R. A. Greenwald, Studies of conjugate plasma 
convection in the vicinity of the Harang discontinuity. J. Atmos. Terr. Phys., 53, 249-263, 1991.

Dungey, J. W., Interplanetary magnetic field and the auroral zones, Phys. Rev. Lett., 6, 47-48, 1961.

Etemadi, A., S. W. H. Cowley, M. Lockwood, B. J. I. Bromage, D. M. Willis, and H. Lühr, The dependence of high-latitude dayside ionospheric flows in the north-south component on the IMF: a high time resolution correlation analysis using EISCAT "polar" and AMPTE-UKS and IRM data, Planet. Space Sci., 36, 471-498, 1988.

Foster, J. C., An empirical electric field model derived from Chatanika radar data, J. Geophys. Res., 88, 981-987, 1983.

Friis-Christensen, E., Y. Kamide, A. D. Richmond, and S. Matsushita, Interplanetary magnetic field control of high-latitude electric fields and current determined from Greenland magnetometer data, J. Geophys. Res., 90, 1325-1338, 1985.

Greenspan, M. E., P. B. Anderson, and J. M. Pelagatti, Characteristics of the thermal plasma monitor (SSIES) for the Defence Meterological Satellite Program (DMSP) spacecraft S8 through S10, Rep. AFGL-TR-86-0227, Airforce Geophysics Laboratory, Hanscom Air Force base, Mass., 1986.

Greenwald, R. A., K. B. Baker, R. A. Hutchins, and C. Hanuise, An HF phased-array radar for studying small-scale structure in the high-latitude ionosphere, Radio Sci., 20, 63-79, 1985.

Greenwald, R. A., K. B. Baker, J. M. Ruohoniemi, J. R. Dudeney, M. J. Pinnock, N. Mattin, J. M. Leonard, and R. P. Lepping, Simultaneous conjugate observations of dynamic variations in high-latitude dayside convection due to changes in IMF $\mathrm{B}_{\mathrm{y}}, J$. Geophys. Res., 95, 8057-8072, 1990.

Greenwald, R. A., K. B. Baker, J. R. Dudeney, M. Pinnock, T. B. Jones, E. C. Thomas, J.-P. Villain, J.-C. Cerisier, C. Senior, C. Hanuise, R. D. Hunsucker, G. Sofko J. Koehler, E. Nielsen, R. Pellinen, A. D. M. Walker, N. Sato, and H. Yamagishi, DARN/SUPERDARN A global view of the dynamics of highlatitude convection, Space Sci. Rev., 71, 761-796, 1995.

Heppner, J. P., and N. C. Maynard, Empirical high-latitude electric field models. J. Geophys. Res., 92, 4467-4489, 1987.

Holzworth, R. H., and C.-I. Meng, Auroral boundary variations and the interplanetary magnetic field, Planet. Space Sci., 32, 2529, 1984.

Kelley, M. C., The Earth's ionosphere, Academic Press, New York, 1989.

Lester, M., O. de la Beaujardière, J. C. Foster, M. P. Freeman, H. Lühr, J. M. Ruochoniemi, and W. Swider, The response of the large-scale ionospheric convection pattern to changes in the IMF and substorms: results from the SUNDIAL 1987 campaign, Ann. Geophyscae, 11, 556-571, 1993.
Lu, G., A. D. Richmond, B. A. Emery, P. H. Reiff, O. de la Beaujardière, F. J. Rich, W. F. Denig, H. W. Kroehl, L. R. Lyons, J. M. Ruohoniemi, E. Friis-Christensen, H. Opgenoorth, M. A. L. Persson, R. P. Lepping, A. S. Rodger, T. Hughes, A. McEwin, S. Denis, R. Morris, G. Burns, and L. Tomlinson, Interhemispheric asymmetry of the high-latitude ionospheric convection pattern, J. Geophys. Res., 99, 6491-6510, 1994.

Lühr, H., S. Thürley, and N. Klöcker, The EISCAT-magnetometer cross. Operational aspects-first results, Geophys. Surv. 6, 305315, 1984.

Milan, S. E., T. K. Yeoman, M. Lester, M., E. C. Thomas, and T. B. Jones, Initial backscatter occurrence statistics for the CUTLASS HF radars, Ann. Geophysicae, 15, 703-718, 1997.

Nagata, T., Research of geomagnetically conjugate phenomena in Antarctica since the IGY, Mem. Natl. Inst. Polar Res. Jpn., 48, $1-45,1987$.

Oguti, T., Conjugate point problem, Space Sci. Rev., 9, 745-804, 1969.

Reiff, P. H. and J. L. Burch, IMF $\mathrm{B}_{\mathrm{y}}$-dependent plasma flow and Birkeland currents in the dayside magnetosphere 2. A global model for northward and southward IMF, J. Geophys. Res., 90, 1595-1609, 1985.

Rodger, A. S., S. W. H. Cowley, M. J. Brown, M. Pinnock, and D. A. Simmons, Dawn-dusk(y) component of the interplanetary magnetic field and the local time of the Harang discontinuity, Planet Space Sci., 8, 1021-1027, 1984.

Ruohoniemi, J. M., and R. A. Greenwald, Statistical patterns of high-latitude convection obtained from Goose Bay HF radar observatiopns, J. Geophys. Res., 101, 21743-21763, 1996.

Todd, H., S. W. H. Cowley, M. Lockwood, D. M. Willis, and H. Lühr, Response time of the high-latitude dayside ionosphere to sudden changes in the north-south component of the IMF, Planet. Space Sci., 36, 1415-1428, 1988.

Tsunoda, R. T., High-latitude F-region irregularities, a review and synthesis, Rev. Geophys., 26, 719-760, 1988.

Wescott, E., Magnetoconjugate phenomena, Space Sci. Rev., 5, 507-561, 1966.

Wing, S., P. T. Newell, D. G. Sibeck, and K. B. Baker, A large statistical study of the entry of the interplanetary magnetic field Y-component into the magnetosphere, Geophys. Res. Lett., 22, 2083-2086, 1995.

Yeoman, T. K., and M. Pinnock, The high-latitude convection response to an interval of substorm activity, Ann. Geophysicae, 14, 518-532, 1996.

Yeoman, T. K., D. K. Milling, and D. Orr, Pi2 pulsation polarization patterns on the U.K. sub-auroral magnetometer network (SAMNET), Planet. Space Sci., 38, 589-602, 1990. 